\title{
ANÁLISE CONFORMACIONAL POR CÁLCULOS TEÓRICOS DA DISTINCTINA, PEPTÍDEO ANTIMICROBIANO ISOLADO DE ANUROS DA ESPÉCIE Phyllomedusa distincta
}

\author{
Victor H. de Oliveira Munhoz, Antônio F. de Carvalho Alcântara e Dorila Piló-Veloso* \\ Departamento de Química, Universidade Federal de Minas Gerais, 31270-901 Belo Horizonte - MG, Brasil
}

Recebido em 7/2/08, aceito em 8/4/08, publicado na web em 29/4/08

\begin{abstract}
CONFORMATIONAL ANALYSIS BY THEORETICAL CALCULATIONS OF DISTINCTIN, AN ANTIMICROBIAL PEPTIDE ISOLATED FROM Phyllomedusa distincta. Various studies demonstrate that different frog species produce distinct classes of biologically active peptides. These peptides can act as alternative agents against pathogenic bacteria and fungi by membrane permeability. Although studies have recently demonstrated that this process is utterly related to the secondary structure adopted by the peptide (in this case, the $\alpha$-helical structure) when in contact with the bacterial membrane, the detailed mechanism is still unknown. In this work we describe a conformational analysis of distinctin, a heterodimeric peptide isolated from the skin of Phyllomedusa distincta, an anuran found in the Brazilian Atlantic Forest. The study yielded a stable geometry with a high content of the $\alpha$-helical structure both in chains 1 and 2 of distinctin, showing strong interaction between them.
\end{abstract}

Keywords: Phyllomedusa distincta; antimicrobial peptide; conformational analysis.

\section{INTRODUÇÃO}

Peptídeos biologicamente ativos são encontrados em diferentes espécies de anuros, ${ }^{1}$ atuando como agentes alternativos contra bactérias patogênicas e fungos, por permeabilização da membrana bacteriana. ${ }^{2,3} \mathrm{O}$ processo inicia-se basicamente com o peptídeo desestruturado em solução que adota uma estrutura $\alpha$-helicoidal, com seus resíduos catiônicos atraídos eletrostaticamente à membrana. ${ }^{4} \mathrm{O}$ mecanismo detalhado dessas permeabilizações por peptídeos antimicrobianos (AMP) é ainda pouco conhecido., ${ }^{5,6}$ No entanto, tem sido proposto que o peptídeo na forma $\alpha$-helicoidal mantém suas regiões hidrofílicas em contato com os grupos hidrofílicos da membrana lipídica para formar poros. Uma outra proposta sugere interações de sítios hidrofóbicos do peptídeo com regiões hidrofóbicas localizadas na parte central da membrana. Neste último caso, as formas $\alpha$-helicoidais não são requeridas para as interações do peptídeo com a membrana. ${ }^{7-10}$ Assim sendo, o balanço hidrofóbico-hidrofílico de um peptídeo torna-se um fator determinante para compreender as interações lipídeo - peptídeo e, por extensão, interações peptídeo - membrana bacteriana. ${ }^{11-14}$

Diferentes metodologias têm sido empregadas para a análise conformacional de peptídeos, ${ }^{15,16}$ a qual tem sido uma estratégia muito importante na busca de informações sobre suas atividades biológicas, uma vez que muitas destas estão relacionadas a processos de permeabilização de membranas. Os métodos experimentais, principalmente Dicroísmo Circular (DC), difração de raios-X e RMN, têm sido eficientes para este fim. No entanto, o uso desses experimentos pode ser limitado por requerer materiais na forma de monocristais (como no caso da difração de raios$\mathrm{X}$ ), em solução com solvente apropriado ou em meio sólido como no caso da RMN. Para todas essas análises, é necessário um alto grau de pureza e, as vezes, quantidades relativamente grandes de peptídeo. Isso pode restringir o trabalho, uma vez que AMP ocorrem normalmente na natureza em micro-quantidades e, por outro lado, o custo para sintetizá-los é significativamente alto. Como alternativa e, em muitos casos, como técnica complementar, uma

*e-mail: dorila@qui.ufmg.br ferramenta muito utilizada tem sido a busca em bancos de dados de seqüências peptídicas homólogas que apresentam propriedades químicas conhecidas. Essa ferramenta tem sido muito utilizada, pois peptídeos com seqüências semelhantes possuem, em alguma extensão, estruturas secundárias também semelhantes entre si. As estruturas secundárias podem ser previstas ainda por metodologias estatísticas. ${ }^{17-19}$ Essas ferramentas podem ser acessadas pelos bancos de dados Expert Protein Analysis System (ExPASy), ${ }^{20,21}$ Basic Local Alignment Search Tool (Blast), ${ }^{22,23}$ Network Protein Sequence Analysis (NPSA) ${ }^{24,25}$ e MetaServer. ${ }^{26}$

A literatura descreve também o emprego de metodologias teóricas na análise conformacional de peptídeos. ${ }^{27}$ Cálculos teóricos de otimização de geometria em nível de Mecânica Molecular (MM) são os mais empregados normalmente devido à simplicidade de operação e recursos computacionais. ${ }^{28-30}$ Os cálculos semi-empíricos (AM1, PM3 e MNDO) e ab initio (HF e DFT) têm sido relativamente pouco explorados por requererem maiores recursos computacionais, apesar de fornecerem normalmente resultados mais próximos aos experimentais. ${ }^{16}$

A distinctina (1, Figura 1) é um AMP isolado das glândulas da pele de Phyllomedusa distincta, anuro natural da Mata Atlântica brasileira. Esse peptídeo apresenta atividade contra bactérias Grampositivas e negativas e sua estrutura heterodimérica é constituída por cadeias de 22 e 25 resíduos de aminoácidos, com ligação dissulfídica entre seus resíduos de cisteína. ${ }^{31}$ Análises por DC e IV de 1 indicaram um alto conteúdo de folhas $\beta$-pregueadas em solução aquosa. ${ }^{31}$ Por sua vez, as análises por RMN em 2D (TOCSY e NOESY) de 1 em meio aquoso indicaram a ocorrência de várias regiões com formas $\alpha$-helicoidais em ambas as cadeias. ${ }^{32}$

Neste trabalho, nós descrevemos a análise conformacional de $\mathbf{1}$ por três métodos: a partir de informações de homólogos em bancos

E N R E V P P GFT A L I K T L R K C K I I

(Cadeia 1)

NLVS GLIEAR KYLEQLHR KLKN C K V

(Cadeia 2)

Figura 1. Estrutura primária da distinctina (1), com indicação da ligação dissulfídica entre os resíduos de cisteína da Cadeia 1 e Cadeia 2 
de dados, por metodologias estatísticas também em bancos de dados e metodologias teóricas em nível de mecânica molecular (MMFF94) e semi-empírico (PM3). O procedimento foi baseado inicialmente na análise estrutural das cadeias tratadas isoladamente (Cadeia 1 e Cadeia 2) para, depois, realizar a análise de $\mathbf{1}$.

\section{PARTE EXPERIMENTAL}

As consultas a sequiências homólogas foram realizadas para as duas cadeias isoladas, empregando o banco de dados MetaServer. As informações são obtidas pelo emprego de diferentes técnicas de alinhamento dos resíduos, permitindo a comparação e procura por estruturas recorrentes entre os resultados gerados. As homologias de $100 \%$ são as próprias sequiências peptídicas estudadas e, por sua vez, as homologias de $0 \%$ são aquelas com nenhuma identidade com a seqüência estudada.

As previsões de estruturas secundárias por metodologias estatísticas foram realizadas pela consulta ao banco de dados NPSA para as duas cadeias isoladas. ${ }^{24}$ As metodologias de previsão empregadas foram DPM, ${ }^{33} \mathrm{GOR} 1,{ }^{34} \mathrm{GOR} 2,{ }^{35} \mathrm{GOR} 4,{ }^{36} \mathrm{HNNC},{ }^{37} \mathrm{PHD},{ }^{38}$ SIMPA96, ${ }^{39}$ SOPM, ${ }^{40}$ SOPMA $^{41}$ e Secondary Consensus ${ }^{42}$ Outra previsão de estruturas secundárias foi realizada pelo banco de dados ExPASy, utilizando-se os métodos de Chou e Fasman, ${ }^{43}$ Deleage e Roux, ${ }^{33}$ Levitt $^{44}$ e de previsão da natureza das $\beta$-folhas (paralelas ou antiparalelas). ${ }^{45}$ Estas metodologias são mais confiáveis, pois se baseiam no alinhamento de várias seqüências peptídicas.

Para cadeias pequenas, com menos de 90 resíduos de aminoácidos, a metodologia de previsão mais indicada é a PHD. ${ }^{38,46}$ Essa metodologia baseia-se em um tratamento estatístico não-linear, por meio de um sistema de redes neurais, prevendo qual a conformação mais provável por comparações entre seqüências homólogas. Essas previsões são resultantes apenas da estrutura primária e consideram implicitamente o efeito do solvente como meio, uma vez que advêm de dados experimentais. O método PHD é o mais indicado para servir de comparação na modelagem molecular das cadeias por apresentar maior exatidão em previsões de estruturas secundárias.

As regiões de hidrofilia de $\mathbf{1}$ foram investigadas para cada cadeia tratada isoladamente, empregando as metolodologias segundo OMH,${ }^{47}$ Kyte e Doolittle, ${ }^{48}$ Abraham e Leo, ${ }^{49}$ Bull e Breese ${ }^{50}$ Guy, ${ }^{51}$ Miyazawa, ${ }^{52}$ Roseman, ${ }^{53}$ Welling, ${ }^{54}$ Parker (HPLC), ${ }^{55}$ Cowan (HPLC pH 7,5 e 3,4), ${ }^{56}$ Wilson (HPLC), ${ }^{57}$ Chothia, ${ }^{58}$ Eisenberg, ${ }^{59}$ Hopps e Woods, ${ }^{60}$ Manavalan, ${ }^{61}$ Black, ${ }^{62}$ Fauchere, ${ }^{63}$ Janin, ${ }^{64}$ Rao e Argos, ${ }^{65}$ Wolfenden, ${ }^{66}$ Mobilidade de $\mathrm{Rf}^{67}$ e Rose. ${ }^{68}$ As regiões de mínimo de hidrofilia foram consideradas como aquelas regiões hidrofóbicas. Esses métodos baseiam-se normalmente na partição de aminoácidos ou seus análogos entre água e um solvente menos polar, bem como em análises estatísticas da distribuição de resíduos de aminoácidos em proteínas solúveis de estrutura conhecida. Alguns métodos consideram também a influência da estrutura secundária sobre a hidrofobia de certas regiões, uma vez que formas helicoidais em especial têm polarizações devidas às interações intramoleculares do tipo ligação hidrogênio.

Os estudos teóricos foram realizados empregando o pacote computacional SPARTAN ${ }^{69}$ para cálculos em nível de mecânica molecular MMFF94. ${ }^{70-76}$ O pacote computacional GAUSSIAN ${ }^{77}$ foi empregado para cálculos em nível semi-empírico PM3. ${ }^{78}$ Geometrias otimizadas em nível MMFF94 foram utilizadas como modelo inicial para os cálculos de otimização da geometria da Cadeia 1 e Cadeia 2 em nível PM3. Em todos os casos, os cálculos foram realizados para estruturas não ionizadas em suas extremidades e no estado gasoso, sem considerar interações intermoleculares.

A análise conformacional da Cadeia 1 foi realizada por cálcu- los de otimização de geometria (MMFF94 e PM3) de fragmentos dessa cadeia, em etapas sucessivas de adições de aminoácidos na extremidade $N$-terminal de sua sequiência peptídica e re-otimizações de geometria. Na análise conformacional da Cadeia 1, os resíduos de aminoácido foram sendo adicionados no sentido da extremidade $N$-terminal (resíduo de ácido glutâmico) para a extremidade $C$ terminal (resíduo de isoleucina). A busca conformacional de cada fragmento da sequiência peptídica foi realizada por variação do ângulo diedro $\psi\left(\mathrm{N}_{i}-\mathrm{C}^{\alpha}-\mathrm{C}^{\prime}-\mathrm{N}_{i+1}\right)$ envolvendo o último resíduo adicionado. As rotações do ângulo $\psi$ foram realizadas de 90 em 90 graus a partir da geometria do fragmento com $\psi$ igual a 180 graus, resultando em quatro geometrias otimizadas para cada fragmento.

Assim, após otimização de geometria do primeiro resíduo, foi adicionado o segundo, conforme seqüência peptídica dada na Figura 1, e feitas re-otimizações das quatro geometrias desse fragmento contendo apenas dois resíduos. A geometria re-otimizada de menor energia foi utilizada para a adição do terceiro resíduo de aminoácido da seqüência da Cadeia 1 e posterior otimização das quatro geometrias desse fragmento. Esse procedimento foi repetido até otimização de geometria completa da Cadeia 1. Procedimento idêntico foi empregado para a análise conformacional da Cadeia 2.

Para otimização de geometria de $\mathbf{1}$, as geometrias otimizadas de ambas as cadeias em níveis MMFF94 e PM3 foram ligadas pelos resíduos de cisteína. Quatro diferentes geometrias foram geradas variando-se de 90 em 90 graus o ângulo diedro C-S-S-C, que foram otimizadas em níveis de cálculos correspondentes. As análises da estabilidade de formas $\alpha$-helicoidal e folhas- $\beta$ na estrutura de $\mathbf{1}$ foram realizadas considerando ambas as cadeias totalmente nessas duas formas de estrutura secundária.

\section{RESULTADOS E DISCUSSÃO}

\section{Resultados das consultas em bancos de dados}

A busca por homólogos foi realizada empregando o banco de dados MetaServer. Pelas limitações dos programas de busca, a estrutura dimérica de $\mathbf{1}$ não foi considerada, realizando-se as buscas das cadeias tratadas isoladamente. Ambas as cadeias apresentam $100 \%$ de homologia com seqüências depositadas em bancos de dados e que se apresentam predominantemente em formas $\alpha$-helicoidais, conforme análises por RMN em solução. ${ }^{32}$

A consulta ao banco de dados NPSA mostrou que todos os métodos indicam uma região $\alpha$-helicoidal entre os resíduos A11 e L16 da Cadeia 1. Exceto os métodos DPM e GOR4, os demais métodos indicam ainda uma expansão da forma $\alpha$-helicoidal que inclui os resíduos F9 e T10. Nas regiões E1 - P6 e K18 - I22 da Cadeia 1, os métodos indicam estruturas secundárias randômicas e formas indefinidas, respectivamente. Na consulta sobre a Cadeia 2, todos os métodos indicam região $\alpha$-helicoidal entre os resíduos E8 e R18. No entanto, as previsões da estrutura secundária em ambas as extremidades diferem consideravelmente entre as metodologias empregadas.

Na consulta ao banco de dados ExPASy para a Cadeia 1, todos os métodos indicaram região $\alpha$-helicoidal principalmente entre os resíduos T10 e L15. As regiões $\alpha$-helicoidais podem ser encontradas também em E1 - R3 e L16 - K20, porém em proporções relativamente menores. Na região F9 - L15 há probabilidade de ocorrer também a forma folha- $\beta$, com predominância da natureza antiparalela. Além disso, na região E4 - G8 há uma alta probabilidade de ocorrer a forma dobra- $\beta$. Para a Cadeia 2 , todos os métodos indicaram uma região $\alpha$-helicoidal entre $I 7$ e L20, região de folha- $\beta$ entre N1 e L6 de natureza predominantemente antiparalela e dobra- $\beta$ entre K19 e C23. 
A previsão de sítios hidrofílicos nas duas cadeias foi realizada por consultas ao banco de dados ExPASy, empregando 23 metodologias diferentes. O sítio de maior hidrofilia da Cadeia 1 localiza-se nos resíduos R3 e L16 (52,2 e 30,4\% dos resultados, respectivamente). O mínimo de hidrofilia (máximo de hidrofobia) localiza-se no resíduo A11 e P7 (78,3 e 13,0\% dos resultados, respectivamente). Na Cadeia 2, o sítio de maior hidrofilia localiza-se nos resíduos L20, L16 e K19, com 43,5; 13,0 e 13,0\% dos resultados, respectivamente. A hidrofobia localiza-se nos resíduos G5 e S4 (50,0 e $39,3 \%$ dos resultados, respectivamente). Como pode ser observado, as previsões de hidrofilia e hidrofobia por diferentes metodologias convergem para determinadas regiões de cada cadeia.

\section{Resultados dos cálculos teóricos}

A Figura 2 mostra a geometria otimizada em nível PM3 da Cadeia 1. A maior parte de sua estrutura secundária apresenta-se na forma $\alpha$-helicoidal, principalmente as regiões que contêm os resíduos de lisina (K14, K18 e K20), leucina (L12 e L16) e isoleucina (I13 e I21). ${ }^{79} \mathrm{~A}$ distorção torna-se mais acentuada próxima à extremidade $N$-terminal contendo resíduos de prolina e glicina, localizadas em P6, P7 e G8, que desfavorecem normalmente a formação de $\alpha$-hélices. A geometria otimizada em nível MMFF94 da Cadeia 1 apresenta-se semelhante à geometria mostrada na Figura 2. Entretanto, a região próxima ao resíduo $\mathrm{C} 19$ apresenta uma forma $\alpha$-helicoidal mais distorcida em relação geometria otimizada em nível PM3.

Cálculos de otimização de geometria em nível PM3 da Cadeia 1 foram também feitos, partindo de estruturas totalmente na forma $\alpha$-helicoidal e folhas- $\beta$, não realizando variações de ângulos diedros ou de ligação para busca conformacional. A geometria otimizada partindo da estrutura totalmente na forma $\alpha$-helicoidal mostra-se menos distorcida. As formas $\alpha$-helicoidais predominam na geometria, com exceção da região P6 - G8. No entanto, os cálculos MMFF94 mostram que essa geometria apresenta uma energia de $10,1 \mathrm{kcal} / \mathrm{mol}$ maior que a geometria dada na Figura 2.

Os cálculos de otimização de geometria em nível PM3 da Ca- deia 1 partindo da estrutura na forma totalmente folhas- $\beta$ não convergiram, indicando tratar-se de uma conformação pouco favorecida termodinamicamente ou estado de transição. Por sua vez, a geometria otimizada em nível MMFF94 partindo também da estrutura totalmente folhas $-\beta$ mostrou-se em forma de fita altamente estirada, com acentuada torção da cadeia na região contendo os dois resíduos de prolina (P6 e P7), conseqüência do impedimento estérico da cadeia em adquirir uma estrutura com formas $\beta$-pregueadas. Os cálculos MMFF94 mostraram que essa geometria apresenta uma energia de $53,02 \mathrm{kcal} / \mathrm{mol}$ maior que a geometria dada na Figura 2.

A geometria otimizada em nível PM3 da Cadeia 2 (Figura 3) mostra predominância da forma $\alpha$-helicoidal, com uma acentuada distorção próxima aos resíduos L16 - K19. A geometria otimizada em nível MMFF94 mostra-se semelhante à geometria otimizada em nível PM3, porém apresentando a região próxima à extremidade $N$-terminal com forma $\alpha$-helicoidal menos explícita. Nesta região estão presentes resíduos de leucina (L2, L6), valina (V3) e serina (S4), que favorecem formas $\alpha$-helicoidais.

Os cálculos de otimização de geometria da Cadeia 2 partindo da geometria na forma totalmente $\alpha$-helicoidal foram realizados em ambos os níveis de cálculos. A geometria otimizada em nível PM3 apresentou desestruturações nas extremidades (N1 - L6 e R18 - N22), sugerindo que as formas $\alpha$-helicoidais nessas regiões apresentam-se menos favorecidas. A geometria otimizada em nível MMFF94 manteve-se totalmente na forma $\alpha$-helicoidal. Os cálculos MMFF94 mostraram que essa geometria apresenta uma energia de $22,11 \mathrm{kcal} / \mathrm{mol}$ maior que a geometria dada na Figura 3.

Os cálculos de otimização de geometria em nível PM3 da Cadeia 2 partindo da estrutura na forma totalmente folhas- $\beta$ não convergiram. Os cálculos MMFF94 resultaram em uma geometria linear com suaves dobramentos ao longo da sequiência peptídica. Os cálculos MMFF94 mostraram que essa geometria apresenta uma energia de $101,36 \mathrm{kcal} / \mathrm{mol}$ maior que a geometria dada na Figura 3.

A Figura 4 mostra a geometria otimizada em nível PM3 da distinctina 1. Essa geometria apresenta-se essencialmente randômica, com algumas regiões que podem ser classificadas como $\alpha$-hélice

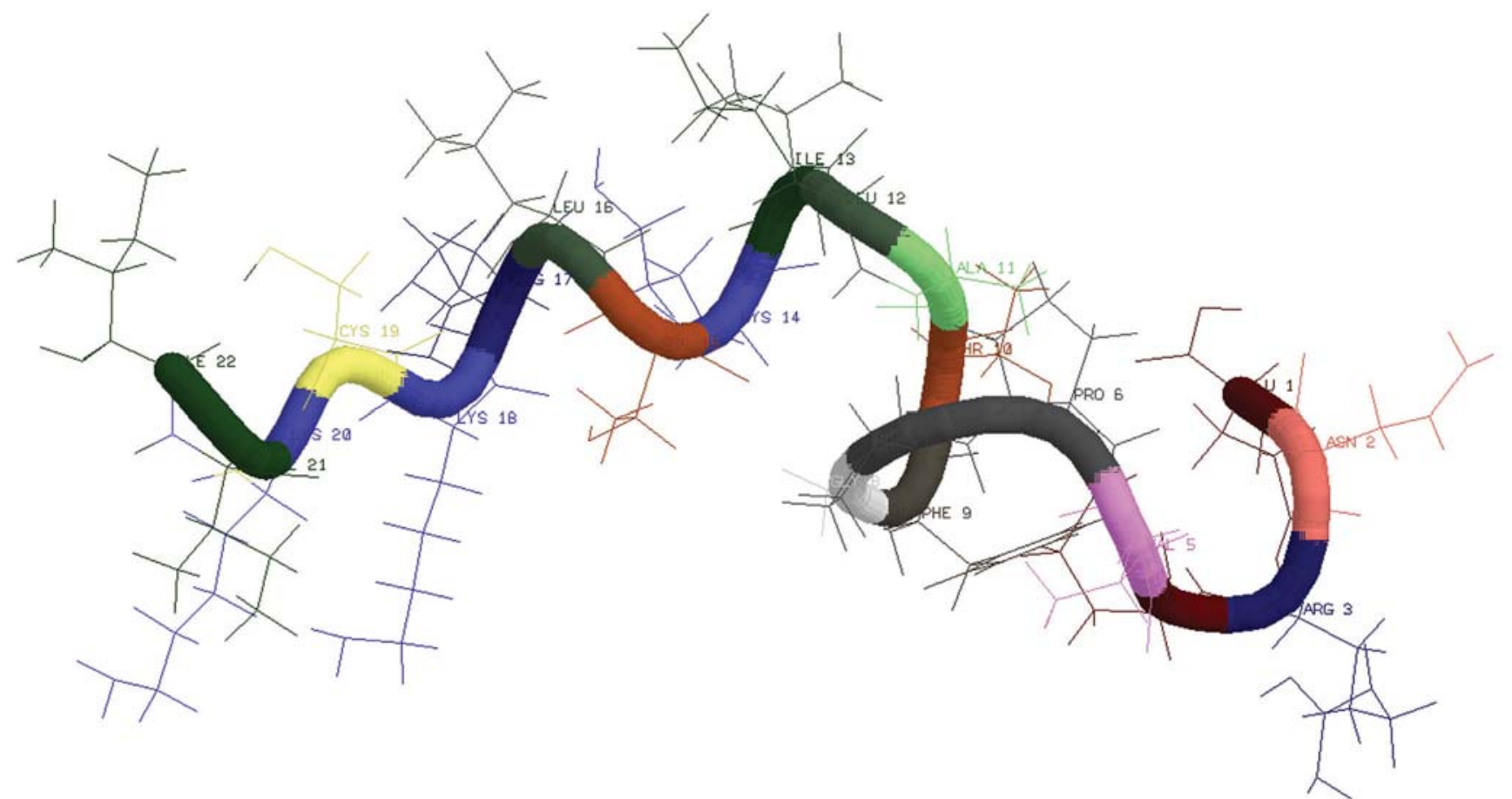

Figura 2. Geometria otimizada em nível PM3 da cadeia 1 da distinctina, cálculos considerando estrutura no estado gasoso, sem interações intermoleculares e extremidades não-ionizadas 


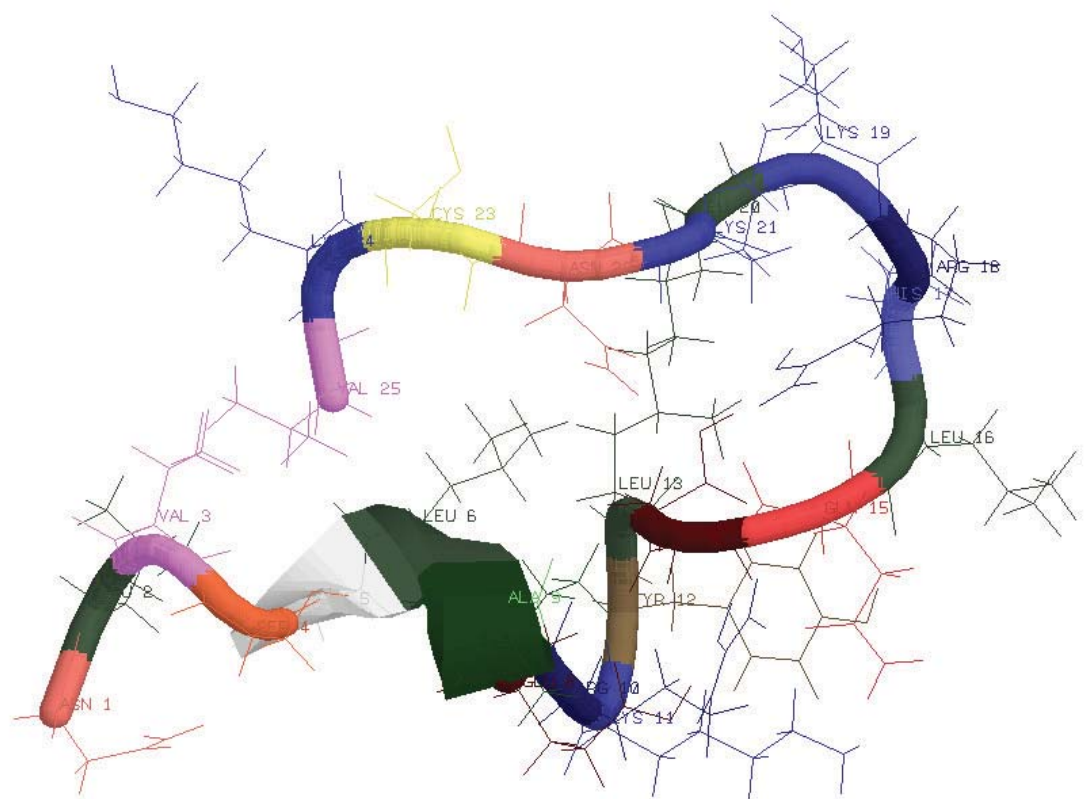

Figura 3. Geometria otimizada em nível PM3 da Cadeia 2 da distinctina, cálculos considerando estrutura no estado gasoso, sem interações intermoleculares e extremidades não-ionizadas

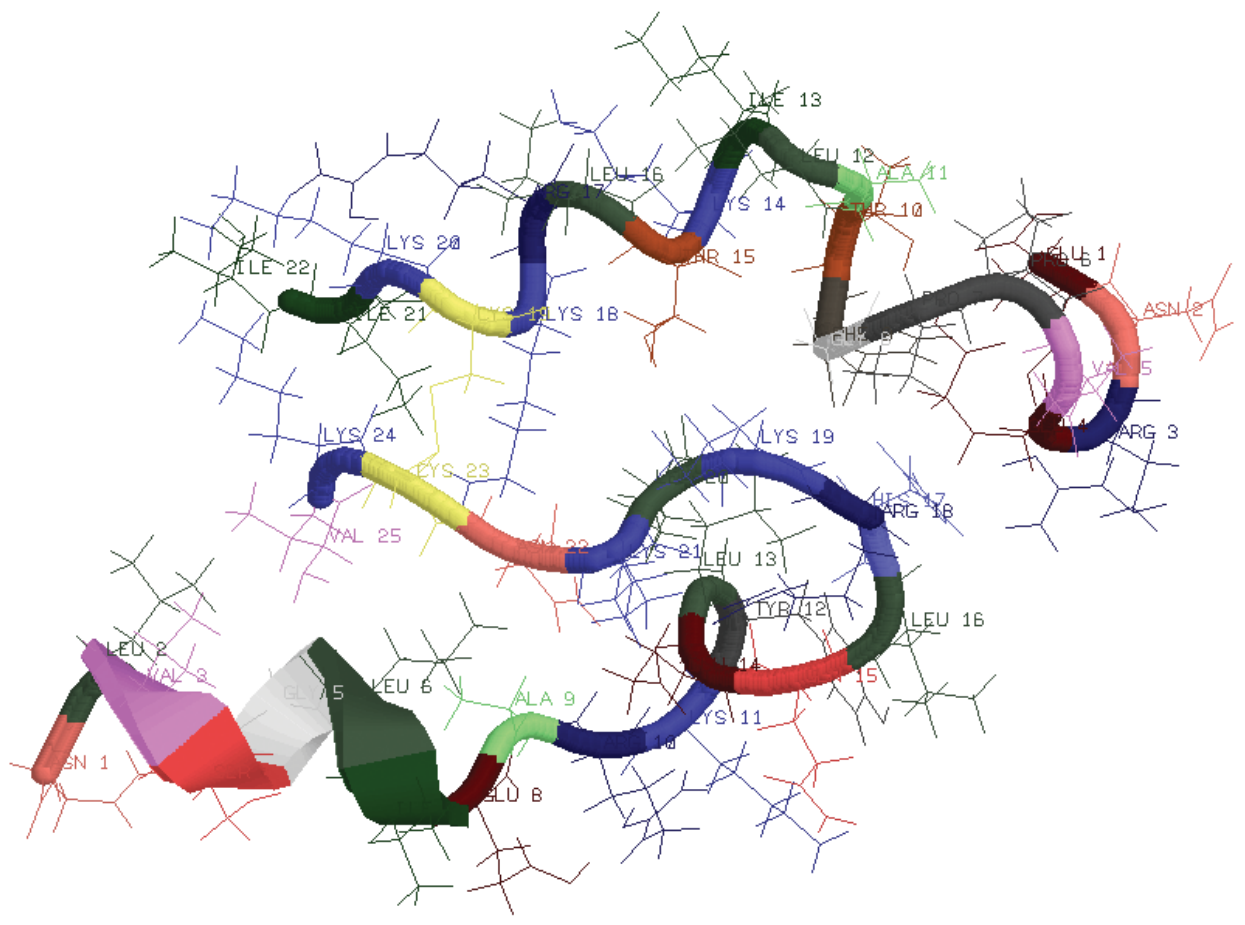

Figura 4. Geometria otimizada em nível PM3 da distinctina, cálculos considerando estrutura no estado gasoso, sem interações intermoleculares e extremidades não-ionizadas

distorcida. A geometria otimizada em nível MMFF94 mostra a Cadeia 2 com regiões $\alpha$-helicoidais menos evidentes. Em ambas as cadeias, formas desestruturadas são observadas nas regiões próximas à ligação dissulfídica. A Cadeia 1 apresenta uma dobra na região T10 - T15, favorecendo interações entre E4 da Cadeia 1 e a ramificação de H17 da Cadeia 2, bem como interações do anel aromático de F9 da Cadeia 1 com a ramificação de K19 da Cadeia 2.

Os cálculos de otimização de geometria em nível PM3 de 1 partindo da estrutura na forma totalmente $\alpha$-helicoidal não convergiram.
A geometria otimizada em nível MMFF94 apresenta em sua maior parte formas $\alpha$-helicoidais distorcidas, exceto nas regiões próximas às extremidades e aos resíduos de prolina (P6 e P7) e glicina (G8) da Cadeia 1, em que predominaram estruturas randômicas. Os cálculos MMFF94 mostraram que essa geometria apresenta uma energia de $56,76 \mathrm{kcal} / \mathrm{mol}$ maior que a geometria dada na Figura 4.

Analisando a estrutura da distinctina 1 obtida por RMN em água, depositada no PDB sob o código $1 \mathrm{XKM},{ }^{80}$ percebe-se que suas Cadeias 1 e 2 possuem um alto conteúdo de formas $\alpha$-hélice. 
Na Cadeia 1, essa estrutura é quebrada devido à presença de uma região flexível compreendida entre os resíduos de P6, P7 e G8. A Cadeia 2 apresenta formas $\alpha$-hélice por toda a sua extensão. Comparando-se primeiramente esses resultados com os obtidos pela metodologia teórica para as estruturas das Cadeias 1 e 2, calculadas separadamente, verifica-se que neste caso ambas apresentam apenas certa tendência em adotar a forma $\alpha$-helicoidal (Figuras $2 \mathrm{e}$ 3 , respectivamente). No entanto, o conteúdo dessa forma nas estruturas obtidas por RMN é mais significativo.

No caso da comparação da estrutura de $\mathbf{1}$ depositada no PDB com a calculada teoricamente, podem ser percebidas semelhanças um pouco maiores entre ambas. Assim, a Cadeia 1 no dímero apresenta maiores torções causadas pela presença dos resíduos de prolina, enquanto a Cadeia 2 apresenta um maior conteúdo de formas $\alpha$-hélice na região próxima à extremidade $N$-terminal (Figura 4). A partir das geometrias otimizadas pôde-se estabelecer a porcentagem de resíduos que participam de formas $\alpha$-hélice (conteúdo de forma $\alpha$-hélice) das Cadeias 1 e 2, bem como da distictina 1 . $\mathrm{Na}$ Cadeia 1 as formas $\alpha$-hélice apresentaram-se distorcidas tanto quando tratada isoladamente, quanto no dímero. Entretanto, a Cadeia 2 apresenta um conteúdo de forma $\alpha$-hélice de $12 \%$ quando tratada isoladamente e de $24 \%$ quando no dímero.

\section{CONCLUSÕES}

Os resultados obtidos a partir do banco de dados ExPASy foram condizentes com a previsão fornecida pelo banco de dados NPSA para a análise estrutural de ambas as cadeias da distinctina. Na Cadeia 1, observa-se um conteúdo significativo de $\alpha$-hélices. $\mathrm{Na}$ região contendo os resíduos de prolina e glicina, observa-se uma quebra dessa estrutura secundária, conforme o esperado, dado o impedimento desses resíduos à adoção da forma helicoidal. $\mathrm{Na}$ Cadeia 2, um conteúdo ainda maior de formas helicoidais pode ser previsto, em conformidade com as metodologias de ambos os ban$\cos$ de dados. As previsões específicas de folhas- $\beta$ de $\mathbf{1}$ indicaram uma preferência em se adotar folhas $\beta$-pregueadas antiparalelas. Esses resultados estão de acordo com as análises por CD e IV de 1, que indicaram um alto conteúdo dessa estrutura secundária em meio aquoso. No entanto, as formas em folhas $\beta$-pregueadas não foram observadas nas estruturas otimizadas, de acordo com as previsões realizadas para as cadeias separadas.

A presença de resíduos apolares como centros hidrofílicos (resíduo L20 da Cadeia 2 e L16 de ambas as cadeias) pode ser devida às suas estruturas secundárias. A polarização inerente às formas $\alpha$ helicoidais e as ligações hidrogênio específicas envolvendo os átomos dos grupos amidas da cadeia peptídica favorecem interações com as moléculas de água. Essas previsões fornecem informações importantes no estudo da interação da distinctina com membranas celulares e no mecanismo de ação sobre bactérias patogênicas.

As geometrias otimizadas de $\mathbf{1}$ partindo de estruturas na forma totalmente $\alpha$-helicoidal mostram-se menos distorcidas. As formas $\alpha$-helicoidais predominam na geometria, com exceção da região P6 - G8 da Cadeia 1 e L16 - L19 da Cadeia 2, estando de acordo com os resultados obtidos a partir dos bancos de dados. Esses resultados estão também de acordo com as análises por RMN da distinctina (1) em meio aquoso, que indicaram a ocorrência de várias regiões com formas $\alpha$-helicoidais em ambas as cadeias. Por outro lado, as geometrias otimizadas de $\mathbf{1}$ partindo de estruturas na forma totalmente folhas- $\beta$ mostraram-se menos favorecidas termodinamicamente. Esses resultados indicam ligações de hidrogênio envolvendo tanto formas helicoidais, com interações intracadeias mais estáveis, quanto formas folha- $\beta$, com interações intercadeias relativamente menos estáveis.
Como a estrutura da distinctina (1) depositada no PDB se apresenta com alto conteúdo de formas $\alpha$-hélice, os resultados dos cálculos MMFF94 e PM3 realizados no estado gasoso podem ser considerados uma boa aproximação, pois indicam sua tendência em adotar estruturação $\alpha$-helicoidal. Assim, a metodologia teórica utilizada mostra-se apropriada à análise de $\mathbf{1}$, podendo, portanto, ser empregada convenientemente no estudo de suas propriedades.

\section{AGRADECIMENTOS}

Ao CNPq, FAPEMIG e CAPES pelas bolsas e apoios financeiros concedidos.

\section{REFERENCIAS}

1. Zasloff, M.; Nature 2002, 415, 389.

2. Rinaldi, A. C.; Curr. Opin. Chem. Biol. 2002, 6, 799.

3. Csordas, A.; Michl, H.; Montsh. Chem. 1970, 101, 182.

4. Bechinger, B.; Biochim. Biophys. Acta 1999, 1462, 157.

5. Shai, Y.; Biopolymers 2002, 6, 236.

6. Bechinger, B.; Crit. Rev. Plant Sci. 2004, 23, 1

7. Brogden, K. A.; Nature Rev. Microbiol. 2005, 3, 238.

8. Oren, Z.; Shai, Y.; Biopolymers 1998, 47, 451.

9. Matsuzaki, K.; Murase, O.; Fujii, N.; Miyajima, K.; Biochemistry 1996, 35, 11361.

10. Shai, Y.; Biochim. Biophy. Acta 1999, 1462, 55.

11. Rao, A. G.; Arch. Biochem. Biophys. 1999, 361, 127.

12. Toke, O.; Peptide Sci. 2005, 80, 717.

13. Kitamura, A.; Kiyota, T.; Tomohiro, M.; Umeda, A.; Lee, S.; Inoue, T.; Sugihara, G.; Biophys. J. 1999, 76, 1457.

14. Verly, R. M.; Rodrigues, M. A.; Daghastanli, K. R. P.; Denadai, A. M. L.; Cuccovia, I. M.; Bloch, Jr., C.; Frezard, F. J. G.; Santoro, M. M.; PilóVeloso, D.; Bemquerer, M. P.; Peptides 2008, 29, 15.

15. Spartan 2004 Windows: Tutorial and User's Guide Wavefunction, Inc., Portland, 2003.

16. Tsai, C. S.; An Introduction to Computational Biochemistry, Wiley-Liss Inc.: New York, 2002.

17. Ostberg, N.; Kaznessis, Y.; Peptides 2005, 26, 197.

18. Apatoff, A.; Kim, E.; Kliger, Y.; PLoS ONE 2006, 1, 113.

19. Schwede, T.; Kopp, J.; Guex, N.; Peitsch, M.; Nucleic Acids Res. 2003, 31,3381 .

20. http://us.expasy.org, acessada em Janeiro 2008.

21. Gasteiger, E.; Gattiker, A.; Hoogland, C.; Ivanyi, I.; Appel, R. D.; Bairoch, A.; Nucleic Acids Res. 2003, 31, 3784.

22. http://www.ncbi.nlm.nih.gov/blast, acessada em Janeiro 2008.

23. McGinnis, S.; Madden, T. L.; Nucleic Acids Res. 2004, 32, W20.

24. http://npsa-pbil.ibcp.fr, acessada em Janeiro 2008.

25. Combet, C.; Blanchet, C.; Geourjon, C.; Deléage, G.; Trends Biochem. Sci. 2000, 25,147 .

26. https://genesilico.pl/meta2/, acessada em Janeiro 2008.

27. Schueler-Furman, O.; Wang, C.; Bradley, P.; Misura, K.; Baker, D.; Science 2005, 310, 638 .

28. Ponder, J. W.; Case, D. A.; Adv. Prot. Chem. 2003, 65, 27.

29. Weber, I. T.; Harrison, W. R.; Protein Eng. 1996, 9, 679.

30. Lomize, A. L.; Flippen-Anderson, J. L.; George, C.; Mosberg, H. L.; J. Am. Chem. Soc. 1994, 116, 1.

31. Batista, C. V. F.; Scaloni, A.; Riegden, D. J.; Lindomar, R. S.; Romero, A. R.; Dukor, R.; Ceben, A.; Talamo, F.; Bloch, Jr.; C.; FEBS Lett. 2001, 494, 85.

32. Raimondo, D.; Andreotti, G.; Saint, N.; Amodeo, P.; Renzone, G.; Sanseverino, M.; Zocchi, I.; Molle, G.; Motta, A.; Scaloni, A.; PNAS 2005, 102,6309

33. Deleage, G.; Roux, B.; Protein Eng. 1987, 1, 289.

34. Garnier, J.; Osguthorpe, D. J.; Robson, B.; J. Mol. Biol. 1978, 120, 97.

35. Garnier, J.; Robson, B. Em Prediction of Protein Structure and the Principles of Protein Conformation; Fasman, G. D., ed., Plenum Press: New York, 2003.

36. Garnier, J.; Gibrat, J-F.; Robson, B.; Methods Enzym. 1996, 266, 540.

37. Guermeur, Y.; Tese de Doutorado, Université de Paris 6, 1997.

38. Rost, B.; Sander, C.; J. Mol. Biol. 1993, 232, 584.

39. Levin, J. M.; Robson, B.; Garnier, J.; FEBS Lett. 1986, 205, 303.

40. Geourjon, C.; Deleage, G.; Protein Eng. 1994, 7, 157.

41. Geourjon, C.; Deleage, G.; Comput. Appl. Biosci. 1994, 11, 681. 
42. Deleage, G.; Blanchet, C.; Geourjon, C.; Biochimie 1997, 79, 681.

43. Chou, P. Y.; Fasman, G. D.; Adv. Enzym. 1978, 47, 45.

44. Levitt, M.; Biochem. 1978, 17, 4277.

45. Lifson, S.; Sander, C.; Nature 1979, 282, 109.

46. King, R. D.; Sternberg, M. J.; Protein Sci. 1996, 5, 2298.

47. Sweet, R. M.; Eisenberg D.; J. Mol. Biol. 1983, 171, 479.

48. Kyte, J.; Doolittle, R. F.; J. Mol. Biol. 1982, 157, 105

49. Abraham, D. J.; Leo, A. J.; Proteins: Struct. Funct. Gen. 1987, 2, 1302.

50. Bull, H. B.; Breese, K.; Arch. Biochem. Biophys. 1974, 161, 665.

51. Guy, H. R.; Biophys. J. 1985, 47, 61.

52. Miyazawa, S.; Jernigen, R. L.; Macromolecules 1985, 18, 534.

53. Roseman, M. A.; J. Mol. Biol. 1988, 200, 513.

54. Welling, G. W.; Weijer, W. J.; Van der Zee, R.; Welling-Wester, S.; FEBS Lett. 1985, 188, 215.

55. Parker, J. M. R.; Guo, D.; Hodges, R. S.; Biochemistry 1986, 25, 5425

56. Cowan, R.; Whittaker, R. G.; Peptide Res. 1990, 3, 75.

57. Wilson, K. J.; Honegger, A.; Stotzel, R. P.; Hughes, G. J.; Biochem. J. 1981, 199, 31.

58. Chothia, C.; J. Mol. Biol. 1976, 105, 1.

59. Eisenberg, D.; Schwarz, E.; Komarony, M.; Wall, R.; J. Mol. Biol. 1984, $179,125$.

60. Hopp, T. P.; Woods, K. R.; Proc. Natl. Acad. Sci. U. S. A. 1981, 78, 3824.

61. Manavalan, P.; Ponnuswamy, P. K.; Nature 1978, 275, 673

62. Black, S. D.; Mould, D. R.; Anal. Biochem. 1991, 193, 72

63. Fauchere, J. -L.; Pliska, V. E.; Eur. J. Med. Chem. 1983, 18, 369.

64. Janin, J.; Nature 1979, 277, 491.

65. Rao, M. J. K.; Argos, P.; Biochim. Biophys. Acta 1986, 869, 197.

66. Wolfenden, R. V.; Andersson L.; Cullis P. M.; Southgate, C. C. F.; Biochemistry 1981, 20, 849.

67. Aboderin, A. A.; Int. J. Biochem. 1971, 2, 537.

68. Rose, G. D.; Geselowitz, A. R.; Lesser, G. J.; Lee, R. H.; Zehfus, M. H.; Science 1985, 229, 834.
69. Spartan 2002: Wavefunction, Inc., Irvine CA \& Schrödinger, Inc., Portland, 1999.

70. Halgren, T. A.; J. Comput. Chem. 1996, 17, 490.

71. Halgren, T. A.; J. Comput. Chem. 1996, 17, 520.

72. Halgren, T. A.; J. Comput. Chem. 1996, 17, 553.

73. Halgren, T. A.; J. Comput. Chem. 1996, 17, 616.

74. Halgren, T. A.; Nachbar, R. B.; J. Comput. Chem. 1996, 17, 587.

75. Halgren, T. A.; J. Comput. Chem. 1999, 20, 720.

76. Halgren, T. A.; J. Comput. Chem. 1999, 20, 730.

77. Gaussian 2003, Revision B.04; Frisch, M. J.; Trucks, G. W.; Schlegel, H. B.; Scuseria, G. E.; Robb, M. A.; Cheeseman, J. R.; Montgomery, Jr., J. A.; Vreven, T.; Kudin, K. N.; Burant, J. C.; Millam, J. M.; Iyengar, S. S.; Tomasi, J.; Barone, V.; Mennucci, B.; Cossi, M.; Scalmani, G.; Rega, N.; Petersson, G. A.; Nakatsuji, H.; Hada, M.; Ehara, M.; Toyota, K.; Fukuda, R.; Hasegawa, J.; Ishida, M.; Nakajima, T: Honda, Y; Kitao, O.; Nakai, H.; Klene, M.; Li, X.; Knox, J. E.; Hratchian, H. P.; Cross, J. B.; Adamo, C.; Jaramillo, J.; Gomperts, R.; Stratmann, R. E.; Yazyev, O.; Austin, A. J.; Cammi, R.; Pomelli, C.; Ochterski, J. W.; Ayala, P. Y.; Morokuma, K. Voth, G. A.; Salvador, P.; Dannenberg, J. J.; Zakrzewski, V. G.; Dapprich, S.; Daniels, A. D.; Strain, M. C.; Farkas, O.; Malick, D. K.; Rabuck, A D.; Raghavachari, K.; Foresman, J. B.; Ortiz, J. V.; Cui, Q.; Baboul, A. G.; Clifford, S.; Cioslowski, J.; Stefanov, B. B.; Liu, G.; Liashenko, A.; Piskorz, P.; Komaromi, I.; Martin, R. L.; Fox, D. J.; Keith, T.; Al-Laham, M. A.; Peng, C. Y.; Nanayakkara, A.; Challacombe, M.; Gill, P. M. W.; Johnson, B.; Chen ,W.; Wong, M. W.; Gonzalez, C.; Pople, J. A; Gaussian, Inc., Pittsburgh PA, 2003.

78. Stewart, J. J. P.; J. Comp. Chem. 1989, 10, 209.

79. Csordes, F. S.; Bright, J. N.; Samson, S. P.; J. Mol. Biol. 2002, 323, 951.

80. Berman, H. M.; Westbrook, J.; Feng, Z.; Gilliland, G.; Bhat, T. N.; Weissig, H.; Shindyalov, I. N.; Bourne, P. E.; Nucleic Acids Res. 2000, 28, 235. 